\title{
Is there an Increased Risk of Periprosthetic Hip Fracture with Polished Tapered Stems Implanted for Neck of Femur Fracture in the Elderly?
}

\author{
Peter Staunton ${ }^{1 *}$, Patrick Dicker ${ }^{1}$ and Michael Donnelly ${ }^{1,2}$ \\ ${ }^{1}$ Royal College of Surgeons in Ireland, Dublin, Ireland \\ ${ }^{2}$ Department of Trauma \& Orthopaedics, Beaumont Hospital, Dublin, Ireland
}

Submission: April 15, 2020; Published: June 25, 2020

*Corresponding author: Peter Staunton, Dept of Trauma \& Orthopaedics, Royal College of Surgeons in Ireland, 123 St Stephen's Green, Dublin 2, Dublin, Ireland

\begin{abstract}
Periprosthetic fracture of the hip is a condition which is costly to manage with high associated morbidity and mortality. Recent studies have suggested that the use of a polished tapered stem for treatment of neck of femur fractures in the elderly may increase risk when compared to use of a matte anatomical stem. We performed a systematic review of the literature to assess this risk. Inclusion criteria required observational studies reporting on a cohort where either polished tapered or matte anatomical stems were implanted to treat neck of femur fractures and periprosthetic fracture rate for the cohort was reported. We identified eight studies where either polished tapered or matte anatomical femoral stems were implanted to treat neck of femur fractures in elderly populations. The combined cohort comprised 7250 subjects with a mean weighted age of 83.17 years. Only one study was identified which compared the two stem types directly in the appropriate cohort. We estimated an increased risk for periprosthetic fracture with polished tapered stem $(2.3 \%)$ when compared to a matte anatomical stem $(0.5 \%)$ when implanted for treatment of neck of femur fracture (p-value 0.0002). Meta-analysis could not be performed due to the absence of two arm studies. Evidence of increased risk for periprosthetic fracture with the use of polished tapered stems in elderly populations after treatment for neck of femur fracture is inconclusive. Joint and hip fracture registry data may potentially be utilised to fully evaluate this risk to identify required changes to practice.
\end{abstract}

\section{Background}

Hip fracture is a global health issue, placing great demand on healthcare resources because of hospital admissions, high morbidity and mortality rates and long term-rehabilitation [1]. Leal et al estimated that the total cost of hip fractures per year in the United Kingdom amounted to GBP 1.1 billion with a sizeable proportion of this figure related to a second hip fracture [2]. While Leal estimated that each hospital admission for initial hip fracture cost on average GBP 14,163 , Phillips et al assessed the cost of treating periprosthetic fracture and estimated a much higher figure of GBP 23,469 [3]. The incidence of periprosthetic fracture continues to rise alongside the trend in primary hip arthroplasty and an increased incidence of peri-prosthetic fractures in the region of $137 \%$ is expected by 2030 [4].

Fleischman and Chen estimated the periprosthetic fracture rate for primary arthroplasty as $1-2.3 \%$ and they also analysed the risk difference between uncemented and cemented stems. They found that the average time to fracture for cemented stems was 6.6 years when compared to 0.5 years for uncemented stems. Revision rate inside 30 days was also noted to be up to 2.2 times higher in the uncemented group as might be expected given the higher fracture rate at implantation and the time required for osteointegration to occur [5]. Over the last 20 years, numerous studies have looked at whether femoral stem design may be an independent risk factor for periprosthetic fracture [6-8]. Studies have both identified and failed to identify the stem as an independent risk factor for periprosthetic fracture although most analyses broadly compare uncemented and cemented stems.

Lindahl and several other authors from Scandinavia have, from joint registry analysis, suggested that implanting a polished stem confers increased risk of periprosthetic fracture in the elderly [811]. A Finnish study from 2005 by Sarvilinna et al was one of the earliest studies to suggest that the wedge-shaped design of the polished tapered stem was a cause of increased periprosthetic fracture risk. The theory has been proposed that a stem working 
by taper slip mechanism, subjected to an abnormal load, such as that experienced in a fall, predisposes to periprosthetic fracture. This risk appeared to be higher compared to a stem working by composite beam principle. This has been suggested to be more common in the context of elderly patients [10] and may be related to the changes that aging bone undergoes which is often generalized under the umbrella of osteoporosis.

Cemented polished tapered stems are, globally, the most common implant used for implantation in the elderly due to the lower risk of intra-operative fracture compared to uncemented stems [12]. Data from the National Joint Registry in the United Kingdom from 2014 indicated that the Exeter V40 (Stryker, New Jersey, USA) (64\%) and CPT (Zimmer, Indiana, USA) (14\%) constituted over $75 \%$ of the cemented femoral stems implanted [13]. The long-term follow-up results for such stems have been shown to be favourable $[14,15]$ and confidence in the stem design has been justified up to this point. However, if it was shown that an increased risk of post-operative periprosthetic fracture can be attributed to one of the most popular stem choices, then this has the potential to change global practice. There is good precedence within arthroplasty for this with an acute deviation away from the widespread use of the Austin Moore prosthesis for hip hemiarthroplasty $[16,17]$. This is nicely reflected within the Australian registry data. In 2003 the Austin Moore was the most recorded implant used for hip hemiarthroplasty with 1988 implanted. In contrast to this the Exeter V40 stem was selected for just 180 of the recorded procedures. Fast forward to 2015 and the shift is clear with 2558 Exeter V40 stems implanted against just 284 Austin Moore prostheses [17].

\section{Study Objectives}

We hypothesised that the use of polished, tapered, cemented femoral stems implanted to treat a neck of femur fracture in elderly patients increases the risk of subsequent periprosthetic fracture when compared to matte anatomical stems.

\section{Methods}

\section{Search Strategy}

We conducted a systematic review by searching databases were using the terms 'arthroplasty, hip, neck of femur fracture, periprosthetic fracture'. Databases searched were Cochrane Library, Embase, Medline, Web of Knowledge, SCOPUS, Google Scholar, OpenGrey, National Library of Medicine (NLM), OpenDOAR, Bielefeld Base. Our search was initially conducted in March 2017 with duplication in April 2017. This was a webbased search with subsequent hand search. Initial search located 335 results which was reduced to 18 studies by screening for title and abstract. Hand search recruited two further full text studies resulting in 20 text papers being analysed. There was no exclusion based on publication date. No non-English language studies required assessment based on initial screening. Only full text articles were included, and abstract only articles excluded where full text could not be accessed. Where further data breakdown within a study was required, the first author was contacted by email with a request for such - this also included relevant abstracts. Articles were excluded where data breakdown was not sufficient to attribute a periprosthetic risk for a defined implant. Studies were excluded where they did not contain a cohort post femoral stem implantation for neck of femur fracture. Studies which grouped stems implanted for both osteoarthritis and neck of femur fracture were excluded if no delineation was made in outcome for post neck of femur fracture versus elective THR. Stems without an ODEP rating were excluded (Figure 1).

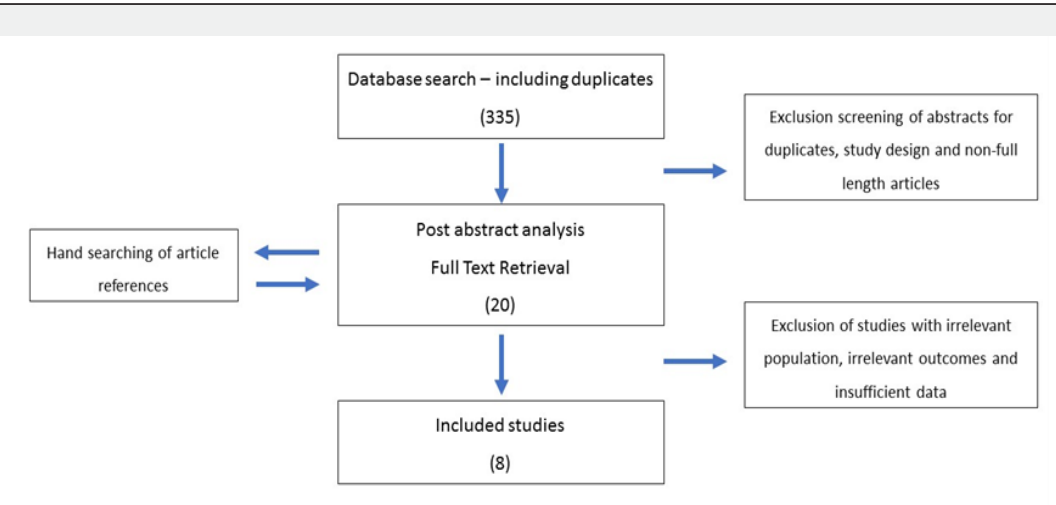

Figure 1: Search flow diagram.

Following our literature search and identification of observational studies to be included, the MOOSE guidelines were applied to conducting the systematic review [17]. The Newcastle Ottawa Scale (NOS) was initially used to evaluate the quality of the included studies but given the paucity of studies available with comparable outcomes per stem type, the NOS scores were expected to be low [18]. To this end the National Institute of Health's quality assessment tool for observational cohorts was also utilised and all studies achieved a quality rating of at least fair with the majority good [19]. No ethical approval was sought as the review was limited to desk research without involvement of any human subjects. 
All studies included were either entirely or partly based on femoral stems implanted for neck of femur fracture. Studies included were required to report data which included the type and number of stems implanted and the number of periprosthetic fractures observed for individual stem type. Only studies with appropriate data for cemented stems implanted for neck of femur fracture were included. Our primary outcome, the incidence rate of periprosthetic fracture, was then calculated for each cohort [20].

\section{Results}

Following our search eight studies were identified that fit our criteria (Table 1). Six of the eight $(75 \%)$ studies looked at outcomes for a polished tapered stem only, while one study $(12.5 \%)$ followed a matte anatomical stem in isolation. Only one study of the eight (12.5\%) contained both a polished tapered stem cohort and a matte anatomical stem cohort. There was a combined total cohort of 7250 subjects with a weighted average age of 83.17 years and weighted average follow up was 40.62 months. Among the included studies the Exeter stem (Stryker Inc) was the most commonly implanted with 4211 (61.2\%) followed by the CPT stem (Zimmer) with 1591 (23.1\%) while the Lubinus (Link) was implanted in 652 (9.4\%) and the JRI (Furlong) in 429 (6.3\%). The Exeter, CPT and JRI stems were all classified as polished, tapered, cemented stems and the Lubinus as an anatomical, matte, cemented stem (Figure 2).

Table 1: Studies included in the systematic review.

\begin{tabular}{|c|c|c|c|c|c|c|c|c|c|}
\hline Author & Paper & Journal & $\begin{array}{l}\text { Year of Pub- } \\
\text { lication }\end{array}$ & Study Type & $\begin{array}{c}\text { Stems As- } \\
\text { sessed }\end{array}$ & $\begin{array}{l}\text { Sample } \\
\text { Size }\end{array}$ & $\begin{array}{c}\text { Estimated } \\
\text { Risk }\end{array}$ & $\begin{array}{l}\text { Mean Fol- } \\
\text { low Up } \\
\text { (Months) }\end{array}$ & $\begin{array}{c}\text { Mean Patient } \\
\text { Age } \\
\text { (Years) }\end{array}$ \\
\hline Phillips et al & $\begin{array}{l}\text { Periprosthetic fractures } \\
\text { around hip hemiarthroplasty } \\
\text { performed for hip fracture } \\
\qquad(60)\end{array}$ & Injury & 2012 & $\begin{array}{l}\text { Retrospec- } \\
\text { tive, obser- } \\
\text { vational }\end{array}$ & $\begin{array}{c}\text { Polished, } \\
\text { tapered (PT) }\end{array}$ & 812 & $0.493 \%$ PT & 51 & 86 \\
\hline Sullivan et al & $\begin{array}{c}\text { Early Complications Following } \\
\text { Cemented Modular Hip Hemi- } \\
\text { arthroplasty (61) }\end{array}$ & $\begin{array}{l}\text { Open Ortho- } \\
\text { paedics }\end{array}$ & 2015 & $\begin{array}{l}\text { Retrospec- } \\
\text { tive, obser- } \\
\text { vational }\end{array}$ & $\begin{array}{c}\text { Polished, } \\
\text { tapered (PT) }\end{array}$ & 429 & $0.233 \% \mathrm{PT}$ & 26 & 83 \\
\hline Mukka et al & $\begin{array}{l}\text { Substantially higher prev- } \\
\text { alence of postoperative } \\
\text { periprosthetic fractures in oc- } \\
\text { togenarians with hip fractures } \\
\text { operated with a cemented, } \\
\text { polished, tapered stem rather } \\
\text { than an anatomic stem (51) }\end{array}$ & $\begin{array}{l}\text { Acta Ortho- } \\
\text { paedica }\end{array}$ & 2016 & $\begin{array}{l}\text { Prospective, } \\
\text { observa- } \\
\text { tional }\end{array}$ & $\begin{array}{l}\text { Polished, } \\
\text { tapered (PT) } \\
\text { Matte, ana- } \\
\text { tomical (MA) }\end{array}$ & 979 & $\begin{array}{l}3.78 \% \mathrm{PT} \\
0.236 \% \\
\text { MA }\end{array}$ & 20 & 86 \\
\hline Raut et al & $\begin{array}{l}\text { Medium to long term follow } \\
\text { up of a consecutive series } \\
\text { of } 604 \text { Exeter Trauma Stem } \\
\text { Hemiarthroplasties (ETS) for } \\
\text { the treatment of displaced } \\
\text { intracapsular femoral neck } \\
\text { fractures. (62) }\end{array}$ & Injury & 2016 & $\begin{array}{l}\text { Retrospec- } \\
\text { tive, obser- } \\
\text { vational }\end{array}$ & $\begin{array}{c}\text { Polished, } \\
\text { tapered (PT) }\end{array}$ & 604 & $1.159 \%$ PT & 49 & 84 \\
\hline Inngul et al & $\begin{array}{c}\text { Postoperative periprosthetic } \\
\text { fractures in patients with an } \\
\text { Exeter stem due to a femoral } \\
\text { neck fracture: cumulative in- } \\
\text { cidence and surgical outcome } \\
\text { (63) }\end{array}$ & $\begin{array}{l}\text { International } \\
\text { Orthopaedics }\end{array}$ & 2015 & $\begin{array}{l}\text { Retrospec- } \\
\text { tive, obser- } \\
\text { vational }\end{array}$ & $\begin{array}{c}\text { Polished, } \\
\text { tapered (PT) }\end{array}$ & 2757 & $2.285 \% \mathrm{PT}$ & 39 & 82 \\
\hline Broden et al & $\begin{array}{l}\text { High risk of early periprosthet- } \\
\text { ic fractures after primary hip } \\
\text { arthroplasty in elderly patients } \\
\text { using a cemented, tapered } \\
\text { polished stem (50) }\end{array}$ & $\begin{array}{c}\text { Acta Ortho- } \\
\text { paedica }\end{array}$ & 2015 & $\begin{array}{l}\text { Prospective, } \\
\text { observa- } \\
\text { tional }\end{array}$ & $\begin{array}{c}\text { Polished, } \\
\text { tapered (PT) }\end{array}$ & 1403 & $3.764 \%$ PT & 48 & 82 \\
\hline Isotala et al & $\begin{array}{l}\text { The Long-Term results of Lu- } \\
\text { binus Interplanta Hemiarthro- } \\
\text { plasty in } 228 \text { Acute Femoral } \\
\text { Neck Fractures. A Retrospec- } \\
\text { tive Six-Year Follow Up (64) }\end{array}$ & $\begin{array}{l}\text { Scandanavian } \\
\text { Journal of } \\
\text { Surgery }\end{array}$ & 2002 & $\begin{array}{l}\text { Retrospec- } \\
\text { tive, obser- } \\
\text { vational }\end{array}$ & $\begin{array}{l}\text { Matte, ana- } \\
\text { tomical (MA) }\end{array}$ & 228 & $\begin{array}{l}0.877 \% \\
\text { MA }\end{array}$ & 75 & 80.3 \\
\hline Kieffer et al & $\begin{array}{l}\text { The Results of Total Hip Ar- } \\
\text { throplasty for Neck of Femur } \\
\text { Fracture in Octogenarians (65) }\end{array}$ & $\begin{array}{l}\text { Journal of } \\
\text { Arthroplasty }\end{array}$ & 2014 & $\begin{array}{l}\text { Retrospec- } \\
\text { tive, obser- } \\
\text { vational }\end{array}$ & $\begin{array}{c}\text { Polished, } \\
\text { tapered (PT) }\end{array}$ & 38 & $0 \%$ & 20 & 84 \\
\hline
\end{tabular}




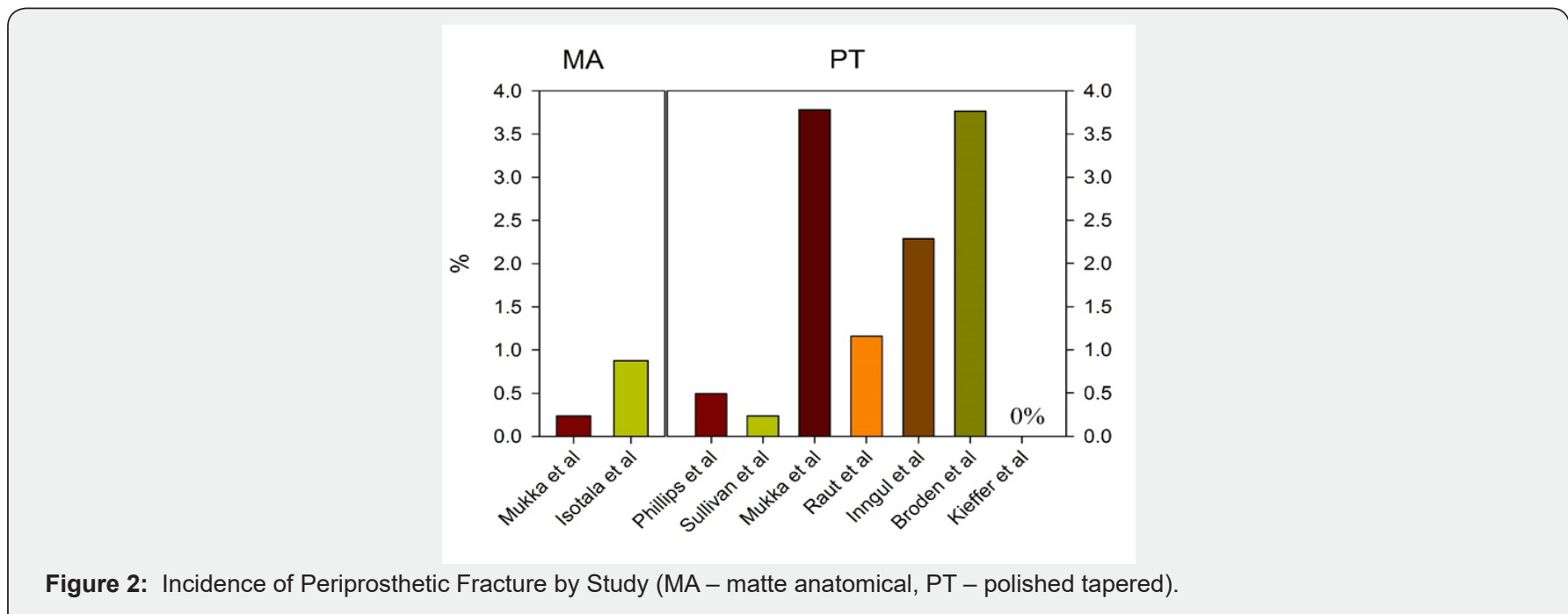

The Newcastle Ottawa Scale is designed to measure the quality of cohort studies based on assessment of cohort selection, cohort comparability and outcome. Selection assesses representativeness of selected cohort, selection of the non-exposed cohort, the ascertainment of exposure and the demonstration that the outcome was not present prior to intervention. All studies included scored well on representativeness as the studies included all case for a fixed time period. Selection of the non-exposed cohort did not apply to the single arm studies. All studies scored on evidence of exposure as operative records were used and likewise on establishing non-presence of outcome prior to intervention as periprosthetic fracture isn't possible in the absence of a prosthesis.

Cohort comparability again did not apply to the single arm studies. This contributed significantly to most studies scoring poorly. Only Mukka et al conducted a two-armed study and this was reflected in a far superior NOS score of 7 . All other single arm studies automatically were deducted 3 points because of the absence of a comparable arm with scores varying from 3-5 (Table 2). Outcome scores were also generally good as outcome was clearly definable. Despite average time to periprosthetic fracture for cemented stems having been estimated at 6.6 years, none of the included studies reached that duration of follow up.

Table 2: Calculated Newcastle Ottawa Scale Scores.

\begin{tabular}{|c|c|}
\hline Study & Newcastle Ottawa Scale Score (Appendix 1) \\
\hline Phillips et al & 5 \\
\hline Sullivan et al & 5 \\
\hline Mukka et al & 7 \\
\hline Raut et al & 4 \\
\hline Inngul et al & 5 \\
\hline Broden et al & 5 \\
\hline Isotala et al & 4 \\
\hline Kieffer et al & 3 \\
\hline
\end{tabular}

The NOS strengths of all studies lay in the documentation of the pre-exposure status, exposure, and outcome by register based collection. This data was collected from various sources including individual centres operative records right through to national registry data. In comparison to the Newcastle Ottawa Scale, the NIH Quality Assessment Tool can be more accurately applied to single arm observational studies. The studies are of generally good quality with the research questions and study populations well defined (Table 3). Cohorts generally include the hospitals catchment area and eligibility is based on the ability to access the appropriate records. As with most of the observational studies sample size is generally based on available data and is not related to power calculation analysis. While included as a measure on the assessment tool, this would not be considered a flaw for these types of studies. The question of sufficient timeframe to see an effect should be considered in these studies and this is one critique of the included studies. Follow up rate is another area which is suboptimal for the included studies. This is universal across the studies however and reflective of the cohort involved.

Table 3: NIH Quality Assessment Scores.

\begin{tabular}{|c|c|}
\hline Study & $\begin{array}{c}\text { National Institute of Health } \\
\text { Quality Assessment Rating } \\
\text { (Appendix 2) }\end{array}$ \\
\hline Phillips et al & Good \\
\hline Sullivan et al & Good \\
\hline Mukka et al & Good \\
\hline Raut et al & Good \\
\hline Inngul et al & Good \\
\hline Broden et al & Good \\
\hline Isotala et al & Good \\
\hline Kieffer et al & Fair \\
\hline
\end{tabular}


The periprosthetic fracture rate was highest for the CPT stem at $3.77 \%$ and the rate of fracture for the Exeter stem was $1.76 \%$. The JRI $(0.2 \%)$ and Lubinus $(0.46 \%)$ stems showed much lower rates of periprosthetic fracture. When the data was pooled (Table 4), the periprosthetic fracture risk for the polished tapered stems was 0.0231 compared to 0.0046 for the matte anatomical stem. This represented a risk difference of 0.0185 giving a relative risk of 5.0 for the polished tapered stem. The odds ratio was calculated at 16.6 with a broad confidence interval. The p-value for the analysis was 0.0002 . These results on the surface at least support the hypothesis regarding increased risk of periprosthetic fracture for our cohort with a polished tapered stem implanted.

Table 4: Pooled estimates of PF risk and risk ratios.

\begin{tabular}{|c|c|c|}
\hline \multicolumn{2}{|c|}{ Risk/Ratio } & Estimate \\
\hline \multirow{2}{*}{ PF Risk } & Polished Tapered & 0.0231 \\
\cline { 2 - 3 } & Matte Anatomical & 0.0046 \\
\hline \multicolumn{2}{|c|}{ Risk Difference } & 0.0185 \\
\hline Relative Risk & 5.0 \\
\hline Odds-ratio (OR) & 16.6 \\
\hline 95\% CI for OR & $2.2-124.2$ \\
\hline P-value* & 0.0002 \\
\hline
\end{tabular}

${ }^{*}$ Cochran-Mantel-Haensel test

The studies included were either single (Raut, Phillips, Inngul, Broden, Kieffer, Isotala) or dual centre (Mukka) studies. Interestingly no registry-based studies were identified that reported data detailed enough to calculate periprosthetic fracture rates for individual stems. Two registry studies were identified and the authors were contacted to retrieve the required data, but no response was received. While collecting data from individual centres would likely limit outcome difference based on variability of the operative procedure, it also limits the variability in implants used. All single centre studies reported data on a single stem type only. Of the 8 studies identified in our review, only one study (Mukka et al, dual centre) had the two study arms of Exeter or $\mathrm{CPT}$ and Lubinis. Consequently, a meta-analysis of risk ratios was not possible.

None of the studies made exclusions other than for patients lost to follow up. The simple endpoint of periprosthetic fracture required no statistical methodology and while not all studies sought peri-prosthetic fracture as their primary endpoint, enough data was provided to calculate this. No confounders were identified in any of the studies. Heterogeneity was grossly affected by the lack of multiple two arm studies making meta-analysis non-contributory.

\section{Discussion}

The Exeter and CPT were the two most common cemented stems from the 2014 UK registry data across combined figures for both total and hemi arthroplasty. Looking at the registry data internationally the Australian Registry provides more data isolated for hemiarthroplasties and trends over the last number of years show a move towards cemented femoral stems with the Exeter stem by far the most popular choice in 2015 with the CPT second most popular [17].

Despite the clear popularity and documented long term success of such implants there may be cause for re-appraisal in certain circumstances such as the elderly neck of femur fracture as suggested in Scandinavian studies [8-11]. The aim of this study was to systematically evaluate whether femoral stems working by the taper slip principle increase the risk of periprosthetic fracture when implanted for neck of femur fracture. We have mentioned that periprosthetic fracture rate is higher when a stem is implanted for neck of femur fracture. Stems designed to work by taper slip principle transmit hip load from the prosthetic head through hoop stresses to the proximal femur with the implant designed to subside in the cement mantle which could be detrimental where large loads are suddenly transmitted to osteoporotic bone in the traumatic setting such as during a further fall.

Cook et al examined the cumulative risk of periprosthetic fracture in THR by age group, independent of implant age, and clearly showed that at 5-year follow up the risk of periprosthetic fracture was more than 3 times higher in those aged over 80 compared to those under 70 years of age [21]. A large-scale study from Sweden [22] performed an analysis on data from the collective Nordic registry. It looked at both cemented and uncemented stems, including 325,730 cemented stems which were either Exeter or Lubinus. It examined relative risk for revision in 34,602 cemented stems implanted for fracture. It gave a periprosthetic fracture rate for cemented stems of $0.07 \%$ at two years but provided no breakdown of periprosthetic fracture rate by stem type. Likewise, Palan et al. [23] analysed the UK registry data with respect to periprosthetic fracture rate, assessing both cemented and uncemented stems implanted as a primary arthroplasty procedure. They reported that the CPT stem (0.45\%) had an almost threefold higher incidence of periprosthetic fracture when compared to the Exeter stem. Unsurprisingly the highest proportion of revisions due to periprosthetic fracture was in the over 80 group but the study made no comment on the indication for arthroplasty and the average age at primary surgery was early 70s. An attempt was made, through contact with the authors, to acquire data breakdown related to implant for fracture but proved unsuccessful.

Gjertsen et al analysed all hemiarthroplasties performed across Norway and Sweden from 2005 to 2010 [24]. The mean ages were 82.6 and 84.1 respectively which represents a cohort similar in age profile to those included in this review. In Norway, the Exeter stem (26\%) was the most popular stem choice ahead of the Charnley (18\%) and uncemented Corail (17.3\%). In Sweden, the Lubinus stem was by far the most popular at $43 \%$ although the Exeter matched the Norwegian figures at $26 \%$. The comparative re-operation rate for periprosthetic fracture was $0.6 \%$ in Norway compared to $0.3 \%$ in Sweden but no data for individual stems was 


\section{Orthopedics and Rheumatology Open Access Journal (OROAJ)}

provided. While it would be tempting to attribute this substantially lower periprosthetic fracture rate to a much higher proportion of matte cemented stems being used in Sweden, the Swedish study had a relatively short mean follow up of 1.5 years.

Across all studies, and irrespective of type of stem implant, periprosthetic fracture risks were all less than 5\%. Indeed, in the selected studies, the Exeter periprosthetic fracture risks were $2 \%$ or less, the CPT periprosthetic fracture risks were slightly less than $4 \%$ while risks for the Lubinis were $<1 \%$. Consequently, periprosthetic fracture is a relatively rare event and large sample sizes (individually or in aggregate) are required for accurate determination of true risks or risk ratios. We nevertheless performed a very exploratory analysis of pooling risk estimates across studies (Table 3). The overall periprosthetic fracture risk for Exeter/CPT/JRI was $2.3 \%$ while the risk for Lubinis was approximately $0.5 \%$.

This suggests that periprosthetic fracture rates are indeed higher for polished tapered stems compared to Lubinis stems i.e. polished and un-polished stems have different risks for periprosthetic fracture. Pooled estimates of risk ratios suggest a relative risk of 5 and an odds-ratio of 16 - however, there is much uncertainty around these estimates due to rarity of events. Indeed such pooled estimates do not constitute a meta-analysis and are objectionable due to the lack of internal study comparisons. That said, these results suggest that future studies comparing periprosthetic fracture risks in polished and un-polished stems may be worthwhile. Perhaps, such studies do not necessarily need to be prospective in nature due to the rarity of periprosthetic fracture e.g different study designs such as case-control studies or retrospective database evaluations may be better placed to yield differences in adverse events between polished and un-polished stems.

None of the studies made exclusions other than for patients lost to follow up. The simple endpoint of periprosthetic fracture required no statistical methodology and while not all studies sought peri-prosthetic fracture as their primary endpoint, enough data was provided to calculate this. No confounders were identified in any of the studies. Heterogeneity was grossly affected by the lack of multiple two arm studies making meta-analysis non-contributory.

\section{Conclusion}

This systematic review sought to evaluate whether the risk of periprosthetic fracture is increased when a polished tapered femoral stem is implanted to treat neck of femur fracture in the elderly when compared to the use of a matte anatomical femoral stem, however, the data available currently is insufficient to definitively answer this question. Further dedicated large-scale studies are required to guide clinicians as to which stem type might reduce the risk of periprosthetic fractures in this particularly atrisk population.

\section{Disclosures}

None.

\section{References}

1. Hartholt KA, Oudshoorn C, Zielinski SM, Burgers P, Panneman MJM, et al. (2011) The Epidemic of Hip Fractures: Are we on the Right Track? PLoS ONE 6(7).

2. Leal J, Gray AM, Prieto-Alhambra D, Arden NK, Cooper C, et al. (2016) Impact of hip fracture on hospital care costs: a population-based study. Osteoporos Int 27(2): 549-558.

3. Phillips JR, Boulton C, Morac CG, Manktelov AR (2011) What is the financial cost of treating periprosthetic hip fractures? Injury 42(2): 146-149.

4. Kurtz S, Ong K, Lau E, Mowat F, Halpern M (2007) Projections of primary and revision hip and knee arthroplasty in the United States from 2005 to 2030. J Bone Joint Surg Am 89(4): 780-785.

5. Fleischman AN, Chen AF (2015) Periprosthetic fractures around the femoral stem: overcoming challenges and avoiding pitfalls. Annals of Translational Medicine 3(16): 234.

6. Franklin J, Malchau H (2007) Risk factors for periprosthetic femoral fracture. Injury 38(6): 655-660.

7. MP Abdel, C D Watts' M T Houdek, D G Lewallen, D J Berry (2016) Epidemiology of periprosthetic fracture of the femur in 32644 primary total hip arthroplasties. BJJ 98(B): 461-467.

8. Sarvilinna R, Huhtala H, Pajamaki J (2005) Young age and wedge stem design are risk factors for periprosthetic fracture after arthroplasty due to hip fracture. A case-control study. Acta orthopaedica 76(1): 5660.

9. Lindahl $\mathrm{H}$ (2007) Epidemiology of periprosthetic femur fracture around a total hip arthroplasty. Injury 38(6): 651-654.

10. Broden C, Mukka S, Muren O, Eisler T, Boden H, et al. (2015) High risk of early periprosthetic fractures after primary hip arthroplasty in elderly patients using a cemented, tapered, polished stem. Acta orthopaedica 86(2): 169-174.

11. Mukka S, Mellner C, Knutsson B, Sayed-Noor A, Skoldenberg O (2016) Substantially higher prevalence of postoperative peri-prosthetic fractures in octogenarians with hip fractures operated with a cemented, polished tapered stem rather than an anatomic stem. Acta orthop 87(3): 257-261.

12. Yli-Kyyny T, Ojanpera J, Venesmaa P, Kettunen J, Miettinen H, et al (2013) Perioperative complications after cemented or uncemented hemiarthroplasty in hip fracture patients. Scand J Surg 102(2): 124128.

13. The National Hip Fracture Database National Report 2010

14. Park JY, Han HJ, Baik SJ, Kweon SH (2015) Long-term Outcome of Polished Stems in Total Hip Arthroplasty. Hip Pelvis 27(2): 83-89.

15. González Della Valle A, Comba F, Zoppi A, Salvati EA (2006) Favourable mid-term results of the VerSys CT polished cemented femoral stem for total hip arthroplasty. International Orthopaedics 30(5): 381-386.

16. Fang C, Liu RP, Lau TW, Leung A, Wong TM, et al. (2016) Is It Time to Phase Out the Austin Moore Hemiarthroplasty? A Propensity Score Matched Case Control Comparison versus Cemented Hemiarthroplasty. BioMed research international 2016: 7627216.

17. National Joint Replacement Registry Hip, Knee \& Shoulder Arthroplasty Annual Report 2016. 
18. Stroup DF, Berlin JA, Morton SC, Olkin I, Williamson GD, et al. (2000) Meta-analysis of observational studies in epidemiology: a proposal for reporting. Meta-analysis Of Observational Studies in Epidemiology (MOOSE) group. Jama 283(15): 2008-2012.

19. Deeks JJ, Dinnes J, D’Amico R, Sowden AJ, Sakarovitch C, et al. (2003) Evaluating non-randomised intervention studies. Health technology assessment (Winchester, England) 7(27): iii-x, 1-173.

20. Health NIo. Quality Assessment Tool for Observational Cohort and Cross-Sectional Studies. In: National Heart LaBI, editor. 2014.

21. Cook RE, Jenkins PJ, Walmsley PJ, Patton JT, Robinson CM (2008) Risk factors for periprosthetic fractures of the hip: a survivorship analysis. Clin Orthop Relat Res 466(7): 1652-1656.
22. Thien TM, Chatziagorou G, Garellick G, Furnes O, Havelin LI, et al (2014) Periprosthetic femoral fracture within two years after total hip replacement: analysis of 437,629 operations in the Nordic arthroplasty register association database. J Bone Joint Surg Am 96(19): e167.

23. Palan J, Smith MC, Gregg P, Mellon S, Kulkarni A, et al. (2016) The influence of cemented femoral stem choice on the incidence of revision for periprosthetic fracture after primary total hip arthroplasty: an analysis of national joint registry data. Bone Joint J 98-b(10): 13471354

24. Gjertsen JE, Fenstad AM, Leonardsson O, Engesaeter LB, Karrholm J et al. (2014) Hemiarthroplasties after hip fractures in Norway and Sweden: a collaboration between the Norwegian and Swedish national registries. Hip Int 24(3): 223-230.

\section{Your next submission with Juniper Publishers will reach you the below assets}

- Quality Editorial service

- Swift Peer Review

- Reprints availability

- E-prints Service

- Manuscript Podcast for convenient understanding

- Global attainment for your research

- Manuscript accessibility in different formats ( Pdf, E-pub, Full Text, Audio)

- Unceasing customer service

Track the below URL for one-step submission https://juniperpublishers.com/online-submission.php 